\title{
Estudiar, inventar y conocer el Porto Marghera de Venecia
}

\section{Studying, cataloguing, knowing Porto Marghera of Venice}

\author{
Esther Giani* \\ Unidad de investigación "Áreas en Desuso y Rehabilitación Paisajística", \\ Departamento de Cultura del Progetto, Università luav di Venezia (Italia) \\ giani@iuav.it
} de una larga experiencia como investigadora. Es Doctora (2003) en Composición Arquitectónica y obtuvo su master en el Instituto Berlage. Se graduó en 1998 en Arquitectura en la Universidad de Venecia, con una tesis sobre el paisaje industrial de la ciudad de Marghera. Desde el año 2000 realiza investigación en el grupo "áreas en desuso y paisajes industriales" creado por G. Carnevale con quien colabora. En el 2019, junto a I. Peron publicó "Porto Marghera Atlas", primer compendio sobre Porto Marghera. 


\section{Resumen}

En este artículo, se discute como leer, analizar y conocer un espacio complejo como Porto Marghera, el distrito industrial de la ciudad italiana de Venecia. Los resultados de la investigación académica se presentan como Atlas: un conjunto de descripciones que se muestran en sus diferentes representaciones diagramáticas, para pro-porcionar instrumentos útiles a la hora de descifrar la forma compleja del lugar. El Atlas tiene en cuenta todos lo que se encuentran en la vasta área: edificios, infraestructuras, suelos y espacios libres; los denomina, los pone en un listado, los cataloga, los describe, los ordena, los selecciona según jerarquías manifestadas, pudiendo implementarlas sin limitaciones según las necesidades e hipótesis de lectura. El Atlas se configura como un conjunto de repertorios y colecciones que abren múltiples oportunidades para proyectos de regeneración territorial. El fundamento que ha orientado la recolección del material es el resarcimiento ambiental y funcional.

Palabras claves: Paisaje industrial; Catalogo; Análisis; Investigación por método inductivo

\section{Abstract}

The topic here described is about how a complex area like Porto Marghera - the industrial district of Venice - can be analysed, visualised and understood. The result of this Academic research has been collected as an Atlas that is as a useful tool to decode the highly complex and problematic area. The Atlas gathers the many objects in this broad area (twice bigger than Venice): buildings, infrastructures, grounds, and free spaces. The Atlas nominates, lists, and catalogues them; it describes, orders and sorts data according to hierarchies highlighted depending on the topic searched. The hierarchies can be implemented depending upon the needs and reading hypothesis. The Atlas described in this article is a series of collections and repertoires that cast multiple opportunities for regeneration's projects. The premise that oriented the data research and sort is that of environmental remediation.

Keywords: Industrial landscape; Catalogue; Analysis; Inductive investigation 


\section{Introducción}

El análisis formal de un proyecto sigue trayectorias y métodos diferentes: puede enfocarse hacia una estrategia más semiológica/ estructuralista, desarrollar reflexiones sobre las analogías, desarrollar patrones de observación separados que se pueden superponer (capas o layers), o también se puede considerar de forma más compleja la red de posibles referencias. Dichas trayectorias y métodos, deberían representar una oportunidad autónoma de desarrollo proyectual, siempre y cuando el observador consiga utilizar los proyectos analizados como un acto de reinterpretación poética.

\section{Una hipótesis de trabajo}

Si en el conjunto de objetos arquitectónicos observados se pueden identificar carac-teres y morfologías similares, aunque no directamente relacionadas a unos patrones evidentes, es decir si los proyectos pertenecen claramente a un ámbito figurativo reconocible, entonces será necesario recurrir a un atlas de morfemas que permita identificar la coincidencia de estilemas afines. De la misma manera, será necesario llegar a una simplificación a través de las "repeticiones" (para matrices formales o geométricas), para que finalmente la identificación sea acertada y evidente. Sin embargo, este proceso de extracción (y abstracción) requiere un esfuerzo que expone al investigador a incurrir en malas interpretaciones, desarrollos autónomos y personales que pueden no tener nada que ver con los originales. Estamos en el campo de análisis proyectivos: las estrate-gias inductivas utilizadas reproducen un origen (un "arché") que puede ser otra cosa respecto al objeto investigado. Una derivada.

En la medida en que el desarrollo del análisis "parece" más racional y prudente, menores serán los riesgos de alejarse de la interpretación original.

Por lo tanto, los instrumentos de investigación necesitan ser soportados por sistemas (gráficos) de seguimiento de dichas fases.
Otra hipótesis de trayectoria (en este caso experimental) que sería interesante evaluar, es la comparación de las diferentes obras buscando morfemas repetidos, independientemente de la escala y del tipo de proyección utilizada (es decir, tratando de la misma forma planos, detalles o secciones). Claramente es una operación compleja, porque requiere un nivel de "esprit de géométrie" que permite individualizar y separa sistemas de características similares dentro del inextricable conjunto del proyecto. De esta forma, se podría descubrir que el esquema estructural presenta fuertes analogías con el aparato decorativo, o que el diseño de un solado tiene mucho en común con el detalle de una ventana, etc.

La investigación crítica (tradicionalmente académica) intenta rastrear las influencias figurativas, las referencias (pretextos) utilizadas por el autor estudiado; intenta reconstruir las condiciones en las que la obra se creó: condiciones sociales, históricas, económicas, políticas, etc. Sin embargo, estas informaciones no tienen (o no "siempre" tienen) un fundamento científico objetivo, ya que se encuentra bajo una fuerte exposición a evaluaciones subjetivas y a menudo con referencias que tienen fuentes vagas. Por lo tanto, este trayecto metodológico resulta demasiado limitado para ser considerado como fundamento. El remanente es la obra en sí, en su tangibilidad y en su cánon de representación, como único elemento cierto de la investigación.

El presente artículo propone un estudio cuyo elemento de investigación es el distrito industrial de Porto Marghera. Hemos reconstruido la historia, el marco regulador, la bibliografía entre otras, pero sobre todo, hemos intentado proponer un sistema de comparación entre entidades que parecían presentar características y morfologías afines. También se trabajó en ábacos y matrices para destacar las repeticiones. El hecho de haber establecido umbrales, por los que muchas características puedan incluirse en un ábaco y no en otra colección, llevó finalmente a descartar alguna que otra interpretación, lo que demuestra el potencial del enfoque de los análisis de proyección mencionados. 
Figura 1: Mario Deluigi, Porto Industriale Venezia Marghera, mosaico (1951).

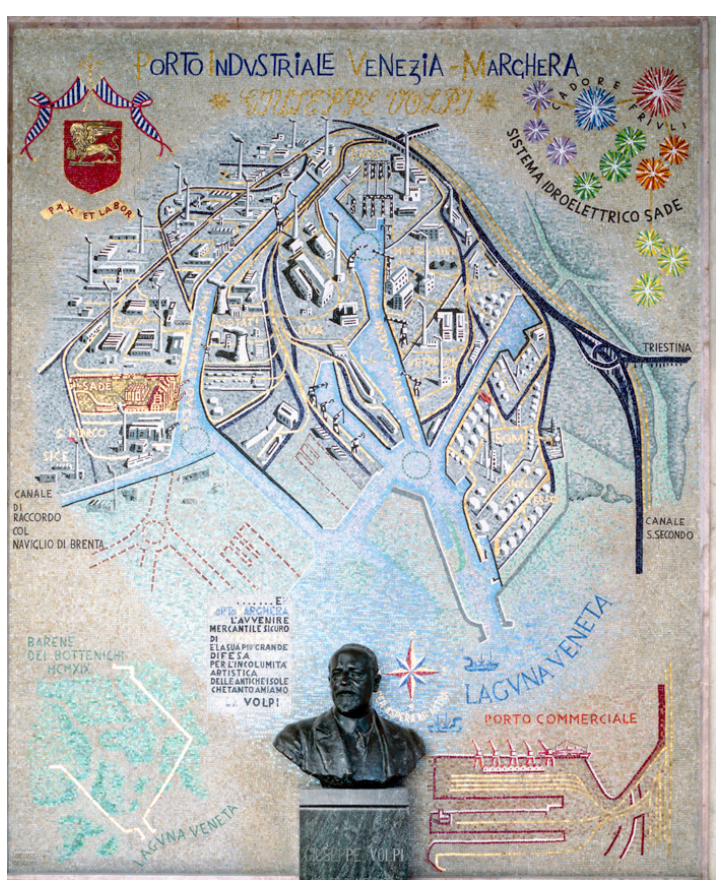

Fuente: oficina termoeléctrica G. Volpi.

El distrito industrial veneciano ha sido enfocado también a través de un método de investigación que evalúe los puntos F.O.D.A., independientemente de la escala.

Las diversas observaciones han sido extraídas, sintetizadas, uniformadas y recopiladas en fichas, y finalmente reconstruidas en colecciones de morfemas afines. El conjunto es un análisis prospectico, obviamente subjetivo, y que proponemos en forma de Atlas ${ }^{1}$.

Encargado por SADE, el mosaico se ubica en el atrio del edificio de la oficina termoeléctrica G. Volpi. En el panel está una cita de Volpi: «Porto Marghera es el futuro seguro para Venecia y su mayor defensa para la seguridad artística de las antiguas islas que tanto amamos.» [È Porto Marghera l'avvenire sicuro per Venezia e la sua piú grande difesa per l'incolumità artistica delle antiche isole che tanto amiamo].

No se trata simplemente de leer estructuras formales implícitas y subyacentes del paisaje industrial veneciano, sino también de leer

1. Giani E., Peron I. (2019). Porto Marghera Atlas. Barcelona Listlab. verdaderos descubrimientos que se deben a los instrumentos (fuentes, normas, inspecciones, planos digitales) y, en la misma medida, al ojo del observador. El Atlas concretiza una investigación de morfemas extrapolados y casi totalmente autónomos con respecto al fenómeno observado. El Atlas propone una lectura procedimental del sitio, aunque resulte ser altamente interpretativa, y aspira a la activación de las sugerencias analógicas que activen los "retentissement"2, es decir los fenómenos de reidentificación de principios formales: figuras que participan de la cultura del investigador. Imágenes presentes en la propia conciencia y que, gracias a las combinaciones permutativas propuestas en el Atlas, puedan encontrar una correspondencia también en el lector. El retentissement pone en marcha la actividad "creativa" del lector, que se identifica con el escritor: «Todos los lectores que releen una obra que aman, saben que las páginas que aman los observan de cerca» ${ }^{3}$.

El material ordenado de esta forma resulta en una colección de pistas sobre posibilidades formales, «pretextos, no inocentes arché. Siempre será el texto, o sea el Proyecto, si es capaz, el único que pueda explicarnos el porque». (Carnevale, 1999)

\subsection{El pretexto Porto Marghera de Venecia}

El proyecto de investigación estudia la cuestión de las áreas industriales (abandonadas, a punto de ser abandonadas, en reducción) en el ámbito urbano, y está validada por argumentos de naturaleza macroeconómica: la densificación y el uso más sostenible del territorio a través de la rehabilitación de áreas en desuso, es un marco de desarrollo plausible para el futuro de los centros urbanos. Los lugares en abandono se entienden en este contexto como volúmenes (fábricas vacías que pueden reincorporarse en un ciclo funcional) y como superficies "de facto"

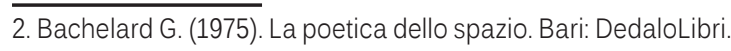

3. Ivi. p. 16. En 1957, Bachelard publica en Paris "La poétique de l'espace" donde se propone presentar una serie de "observaciones fenomenológicas" sobre el espacio imaginado, es decir sobre el espacio como imagen, entendido como lugar repleto de cualidades imaginarias. 


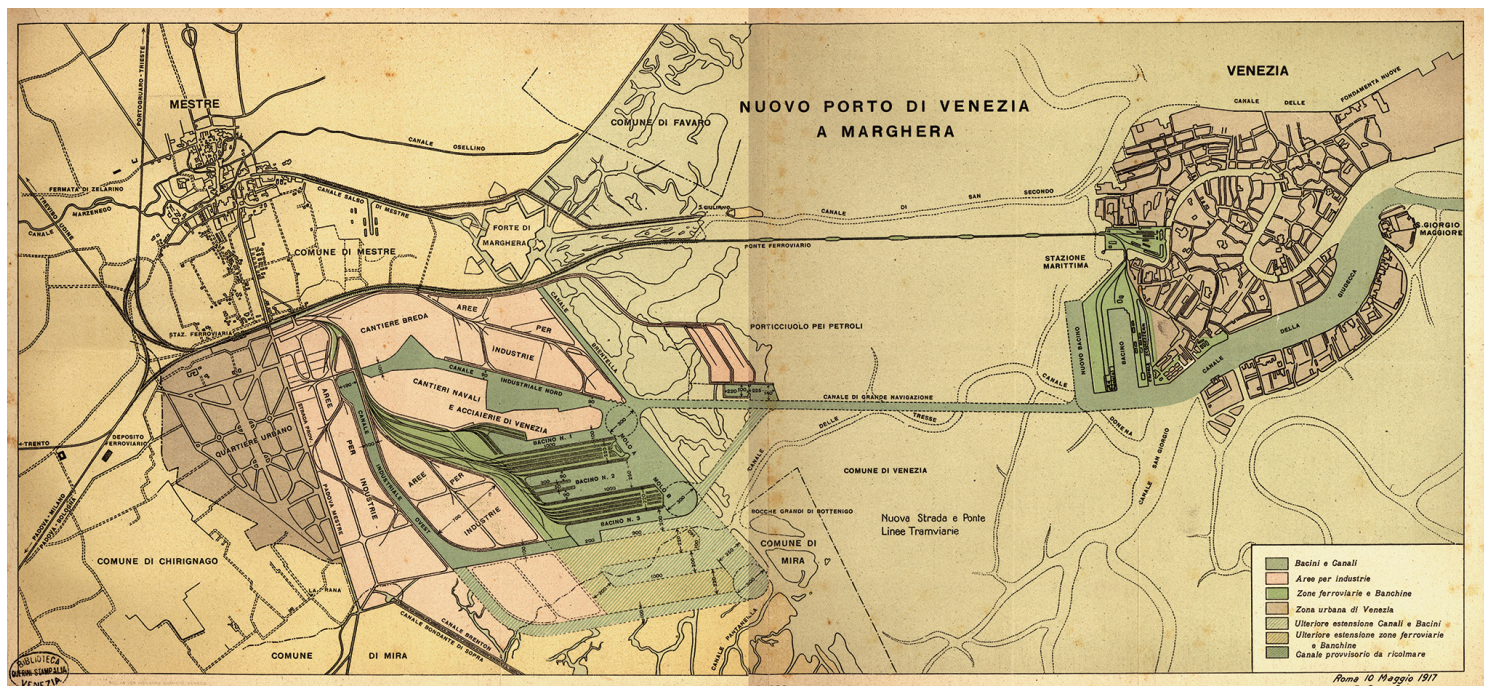

Fuente: Biblioteca Querini Stampalia, Venecia

disponibles en la sociedad. Las potencialidades de un paisaje industrial están al mismo tiempo disputadas y rechazadas en una espiral negativa que no parece tener una solución verosímil, en primera instancia con respecto al territorio que representa un patrimonio para preservar, conservar y entregar a las futuras generaciones.

El tema de la recuperación de las áreas industriales está presente y aceptado en Europa desde los años noventa; sin embargo, la crisis económica y el progreso tecnológico han causado un progresivo descenso de las grandes producciones de la industria de base, reubicando el enfoque en este debate. Por lo tanto, la reflexión que entrelaza los sitios industriales con las intenciones de quien es el encargado de la transformación, tiene raíz principalmente económica: hay necesidad de desincentivar el consumo extensivo del territorio y aumentar la capacidad de amortización de los costes de infraestructuras.

Esta investigación proporciona los datos necesarios para definir los parámetros deselección de los puntos neurálgicos donde poder implantar una posible (y plausible) acción de recomposición del distrito veneciano. Dicho de otra forma: este trabajo relata los objetos que se encuentran en Porto Marghera, tanto obras como de infraestructuras y suelos: los denomina, los enlista, los cataloga, los describe, los ordena, los selecciona según jerarquías manifestadas, pudiéndolas implementar sin limitaciones según la necesidad y la curiosidad. Recopilaciones y colecciones abren el camino a posibilidades proyectuales no infinitos, que están sometidas al requisito vinculante del resarcimiento ambiental. Esta investigación es una "obra abierta" (Eco 1962), que vuelve a poner el enfoque sobre la exploración y el descubrimiento de nuevas oportunidades de proyectos para la rehabilitación territorial, dejándose atrás la anterior propensión a considerarla una actividad exclusiva de los expertos.

Está demostrado que el proyecto de arquitectura puede encargarse de la recaída morfológica de las obras de saneamiento, de manera que la gestión en su totalidad se queda en las manos del director del proyecto, que actúa como director y garante de los estándares de calidad.

El trabajo se ha ejecutado manteniendo firme y claro su fundamento: el análisis es el proyecto. Las pruebas y los hechos analizados hasta ahora han demostrado que sigue siendo imposible la puesta en marcha de un plan global plausible; sin embargo, parece que la estrategia de "acupuntura" (Zenghellis, 2007) sea la más prometedora. Este planteamiento facilita la gestión de realidades individuales, 

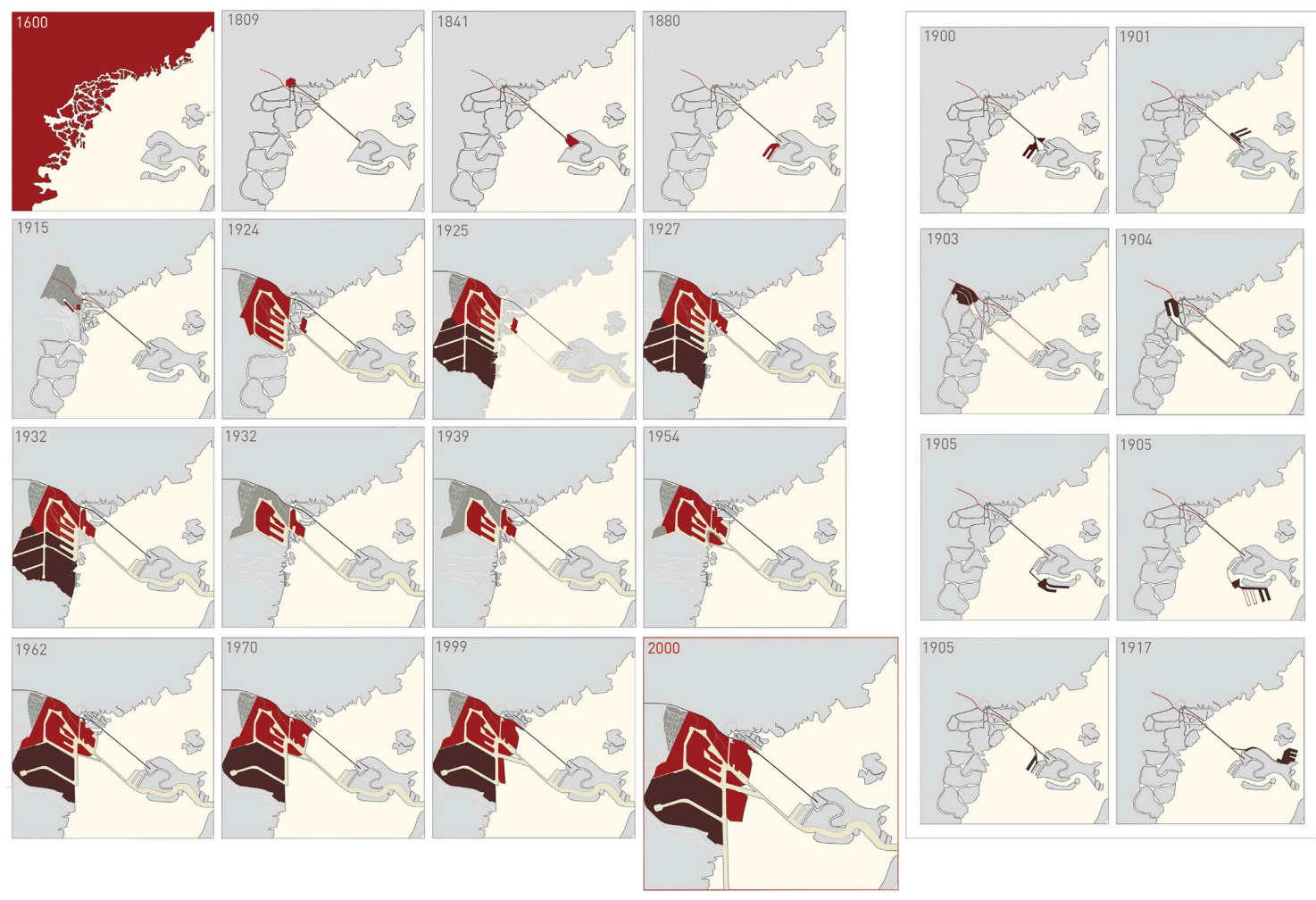

Fuente: Porto Marghera Atlas, 2018

Figura 4: Distrito Industrial de Venezia, Porto Marghera

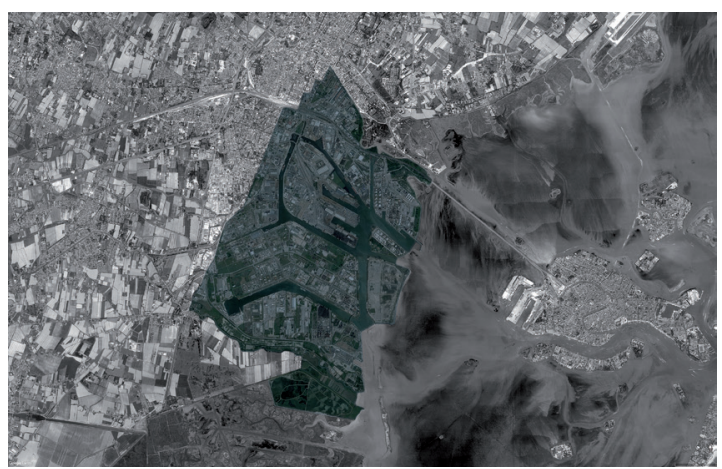

Fuente: Google Maps

que pueden ser administradas de forma autónoma, y de tal manera se facilita la creación de redes y sistemas más complejos. La inevitable recuperación total del área puede planearse a través de intervenciones oportunas y rigurosamente estructuradas, y capaces de interactuar entre ellas: una renovación programada por partes y monitoreada en el tiempo, tiene más posibilidades de ser llevada a cabo con éxito.
Un punto clave en el planteamiento estratégico de esta operación, es limitar daños ulteriores al territorio, dejando obras incumplidas. Entra en juego el rol político del Arquitecto, como responsable de la gestión general del proyecto. Se puede decir que el móvil más importante de este trabajo es ético: identificar los mejores instrumentos proyectuales para que confluyan beneficios diferentes y se compartan las potencialidades, de manera que el patrimonio colectivo pueda ser una finalidad y una oportunidad (también privada).

\section{El asunto de Porto Marghera. Notas históricas}

El distrito industrial veneciano como lugar a disposición de la sociedad, representa un asunto que se mantiene abierto desde su nacimiento (1917). De hecho, la relación de Porto Marghera con el contexto en el que se encuentra se puede considerar ambigua. Tal condición se manifiesta en primer lugar con la ciudad histórica de Venecia, de la que representa su complemento 
Figura 5: El interés estratégico de Porto Marghera, considerado uno de los más infra estructurados de Europa
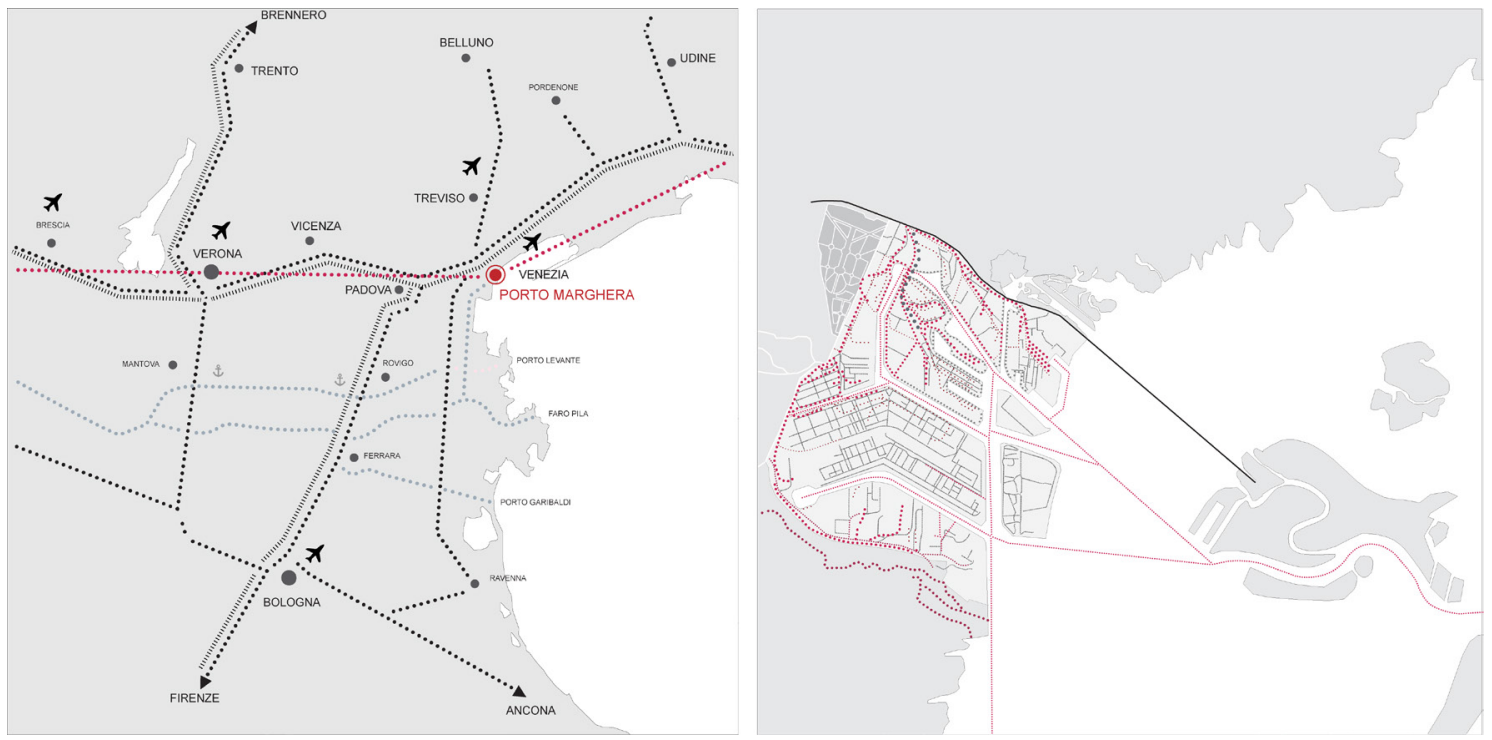

Fuente: Porto Marghera Atlas, 2018

Figura 6: Individualización de las ínsulas definidas por el recorrido de los canales y por la viabilidad: 1 pequeña, 6 medianas, 2 grandes y 2 extra grandes.

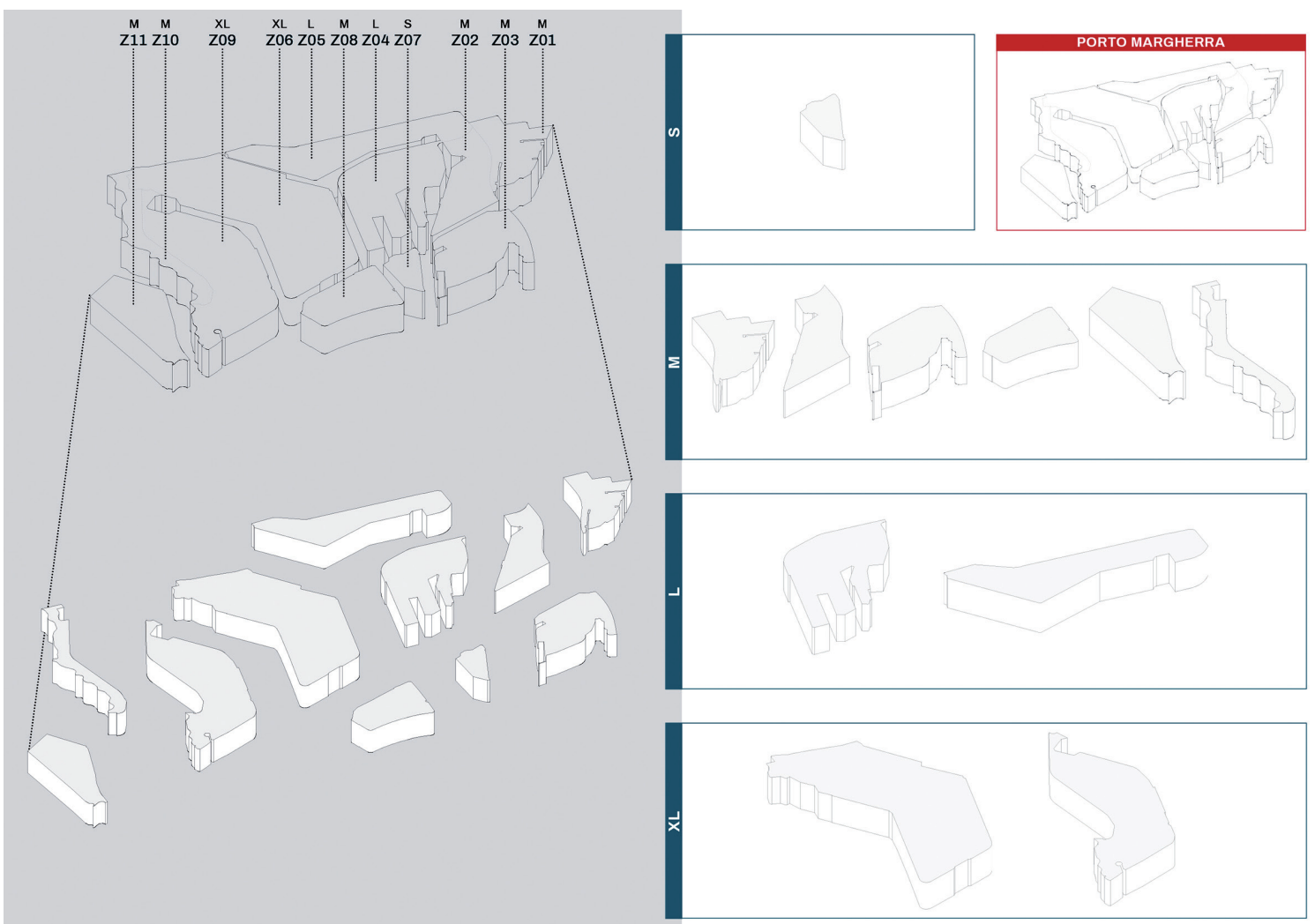

Fuente: Porto Marghera Atlas, 2018

industrial y principal horizonte; también la relación con la Laguna se ve comprometida por la alteración del equilibrio ecosistémico del agua. Por último su presencia daña el paisaje del lado 
peninsular de la ciudad, cuyos característicos paisajes rurales y agrícolas se ven perjudicados. En sus cien años de historia, la productividad ha tenido altibajos hasta llegar a su máximo desarrollo en los años setenta. La reducción de las actividades del distrito en los últimos veinticinco años, ha llevado al nacimiento de innumerables iniciativas de recuperación del área, por parte tanto de políticos como de empresarios y académicos. Paralelamente, hay ambigüedad en las relaciones con la sociedad civil que ve en Porto Marghera una positiva oportunidad en términos de trabajo, pero un mal a raíz de los problemas que conlleva. Sin embargo, no se puede negar que negatividad, pesimismo y resignación son los sentimientos principales por parte de la ciudadanía cuando se habla de su futuro.

\subsection{Marco general}

Para entender con más claridad cuáles son los orígenes, las oportunidades y las contradicciones de este territorio, es oportuno entender su desarrollo histórico, desde la génesis de la que se conoce como "Operación Porto Marghera", hasta los eventos que se han protagonizado, a veces perseguidos y otros negados.

En líneas generales, el estado morfológico de distrito industrial veneciano define sus dimensiones actuales entre la primera y la segunda guerra mundial, por la demanda de productos de química básica y de la industria siderúrgica. ${ }^{4}$

Sin embargo, las razones políticas, administrativas y económicas que han llevado a esta estructura tienen raíces todavía más antiguas, atribuibles a hechos históricos que influirán en el cuadro geopolítico internacional (como por ejemplo la apertura del canal de Suez que cambió el rol de los intercambios comerciales en el Mediterráneo) cuyas consecuencias han llevado a una general reorganización de la gestión de los puertos y del comercio de la ciudad. Gracias a un nuevo sistema de infraestructuras funcional a la instalación portuaria,

4. A partir de la química de base y de la siderurgia, se desarrollaran varios subsectores de producción que en los años se colocan de forma estable en Porto Marghera. procuró optar por una expansión hacia el lado peninsular de la ciudad, creando las primeras instalaciones del tejido industrial del distrito. En cualquier caso, no ha sido solo la rápida modernización de las instalaciones portuarias la que ha determinado el nacimiento de Porto Marghera: la expansión peninsular se concretiza cuando consigue convertirse en un lugar capaz de responder a alguna que otra necesidad de Venencia a principio del siglo veinte, como invertir en viviendas y en el desarrollo de actividades de producción local favoreciendo la competitividad (técnica y económica) entre los puertos del Mediterráneo. En 1917, año de nacimiento de Porto Marghera, se constituye el Sindicado de Estudios para las Empresas Electrometalúrgicas que junto con la administración local, y el gobierno central, definen las guías para el desarrollo del puerto industrial. En 1919 empieza la realización del distrito con un proyecto de Coen Cagli, y en 1922 se inaugura el gran canal de navegación paralelo a las vías del puente ferroviario (el canal Vittorio Emanuele), completando así la infraestructuración del barrio portuario, atrayendo en Marghera todos los grupos industriales italianos de mayor prestigio.

A esta primera área industrial, núcleo histórico de la industria veneciana, se añade una expansión posterior a la segunda guerra mundial. En los años cincuenta se saneó una amplia porción de barene ${ }^{5}$, al sur-oeste de la isla del puerto comercial.

El Plan General de Ordenación en 1956 se puso en acto en 1963, cuando se dispuso que en Porto Marghera podrían instalarse establecimientos contaminantes, aunque en los hechos esto ya había pasado ${ }^{6}$.

Transcurrido un periodo de máxima productividad en los años setenta, empieza un declive

\footnotetext{
5. Las barene son áreas especiales de la laguna con tendencia a sufrir graves inundaciones debidas a las mareas.

6. En el Plan de Reglamentación de 1956, se explicitaba que «en la zona industrial tendrán lugar prevalentemente las instalaciones que producen vibraciones y difunden en el aire humo, polvo o exhalaciones dañinas a la vida humana, que descargan sustancias venenosas y producen ruido» (normativa de actuación, Articulo 15, Pár. 3).
} 
Figura 7: Los datos desagregados han sido re-mapeados y diagramados por tipología y argumento. En este caso se ha mapeado la contaminación del área atreves una matriz: macro áreas - contaminación del suelo - contaminación de las aguas subterráneas.
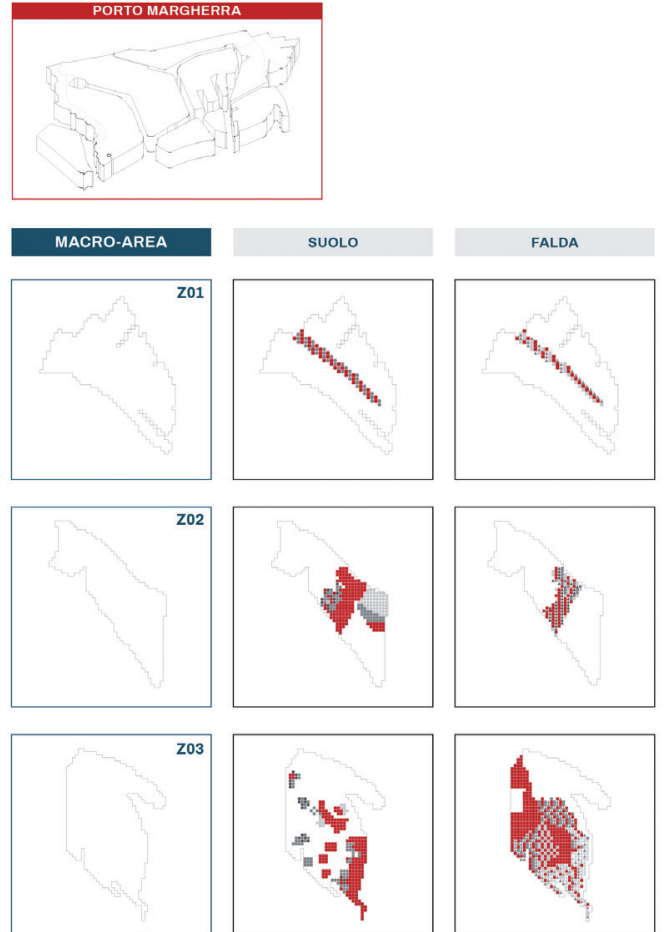
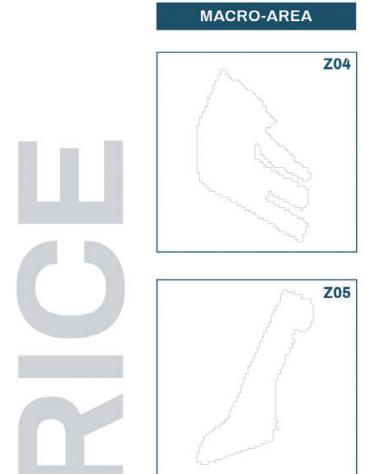

\section{5}
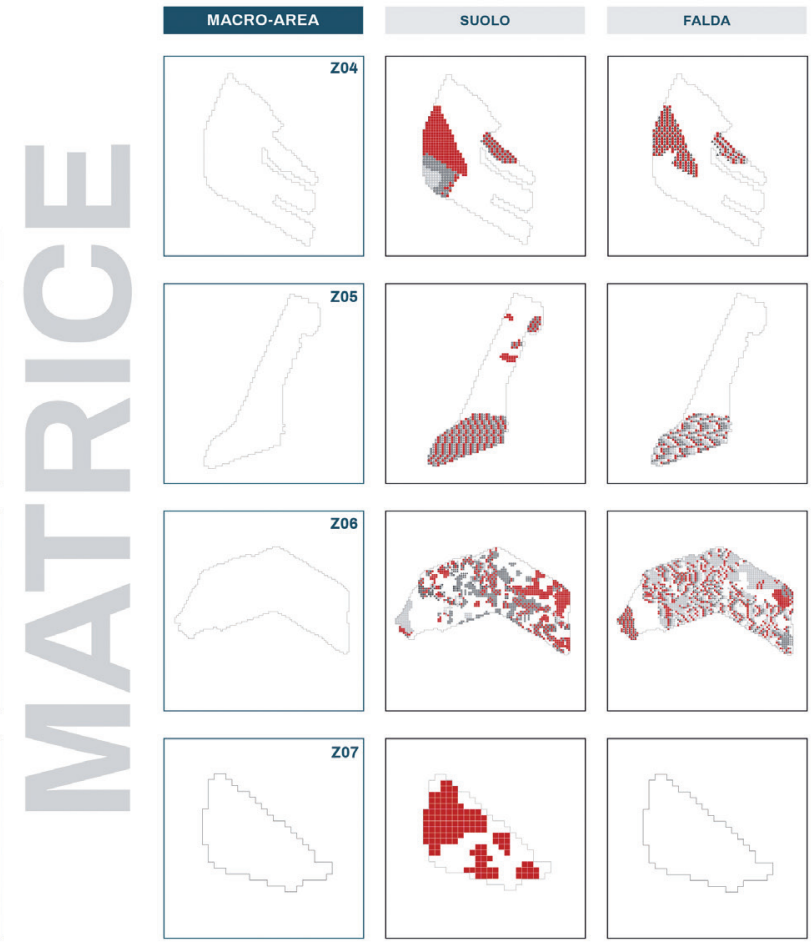

Fuente: Porto Marghera Atlas, 2018

del distrito abriendo el camino para una larga fase, todavía en curso, de reducción del personal trabajador y de abandono de algún que otro sector de producción. Por estos motivos, la realización de la tercera zona industrial, como extensión adicional del distrito, empezó pero nunca se llevará a cabo ${ }^{7}$.

Lo que pasó en Porto Marghera no cubre solo sus inicios y su desarrollo, sino también el actual contexto geográfico, político y gubernamental en relación a la "ciudad metropolitana". El interés estratégico de este territorio, considerado uno de los más infraestructurados de Europa $^{8}$, se perfila a través de las relaciones

7. Solo en el establecimiento petroquímico había 15.000 trabajadores. En su periodo de máxima productividad, en Porto Marghera trabajaban alrededor de 45.000 personas.

8. «Porto Marghera ocupa hoy [años 2000] más de 2.000 hectáreas, 1.600 entre ellos son áreas industriales (toda Venecia, incluyendo la cuenca de San Marco y las islas de San Giorgio y Giudecca, ocupan 700 hectáreas), recorridos por canales y espejos de agua (340 hectáreas), atravesados por carreteras y ferrovías ( 80 hectáreas), y rodeadas de áreas públicas (40 hectáreas) que alojan el puerto comercial (120 hectáreas), cruzados por $18 \mathrm{~km}$ de canales marítimos y $32 \mathrm{~km}$ de canales entre el distrito industrial veneciano y el sistema de infraestructuras supralocal (Corridoio $5)^{9}$. Se trata de un sistema infraestructural de un tamaño mucho mayor de las simples fronteras de la ciudad o de la provincia de Venecia: solo hace falta tener en cuenta que el sistema aeroportuario de la ciudad es el cuarto en Italia por carga y el tercero para trayectos y pasajeros después de los aeropuertos de Roma y Milán.

Si por una parte parece innegable la dimensión supralocal que resulta da los datos analizados, siguen permaneciendo ambigüedades sobre la determinación de las fronteras dentro del territorio metropolitano. De la misma forma no se han solucionado las contradicciones en las morfologías urbanas, extremadamente

industriales, con por lo menos 100 paradas $13.000 \mathrm{~m}$ lineares de muelle, con $40 \mathrm{~km}$ de calles interiores y $135 \mathrm{~km}$ de red ferroviaria interna.»

Bettin, G. Dianese, M. (2002). Petrolkiller. Milan: Feltrinelli. p.109.

9. Pasillo Paneuropeo multimodal definido en 1994: es una vía de comunicación (de productos y personas), eje de ferrovía y autopistas de Europa central que conecta Kiev con Lisboa. 


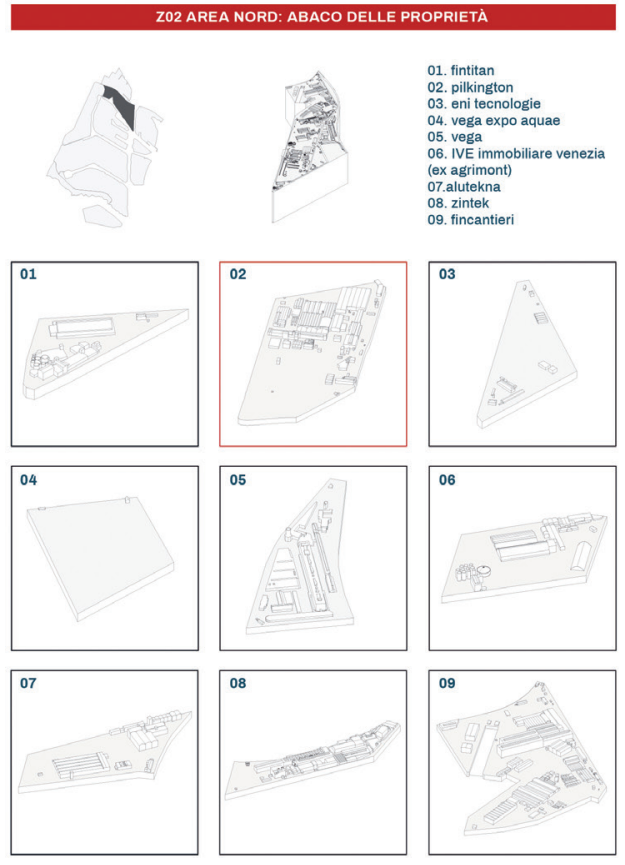

Fuente: Porto Marghera Atlas, 2018

heterogéneas, que esta dirección institucional debería entender y gestionar.

Efectivamente Venecia es muy diferente respecto a las otras ciudades metropolitanas de Italia y Europa, donde no hay incertidumbre sobre centralidad y jerarquías. Este territorio presenta una dispersión más que evidente: "¿La metamorfosis de Italia, de tierra de ciudades en una nebulosa de periferias, erosionará también la unicidad de Venecia? La burocrática invención de las ciudades metropolitanas que se ha establecido hasta en la Constitución (2001) establece el triunfo de la extensión urbana y lo promociona como estructura portante del tejido habitacional del País ${ }^{10}$. Hay que preguntarse ahora si el complejo cuadro histórico, político y ambiental no condiciona solo tiempos y costes de la rehabilitación, si no que esté influyendo en las formas y funcionalidades de las obras de recuperación en curso

10.Settis, S. (2014). Se Venezia muore. Turín: Einaudi. p.89.

Textto original en Italiano)

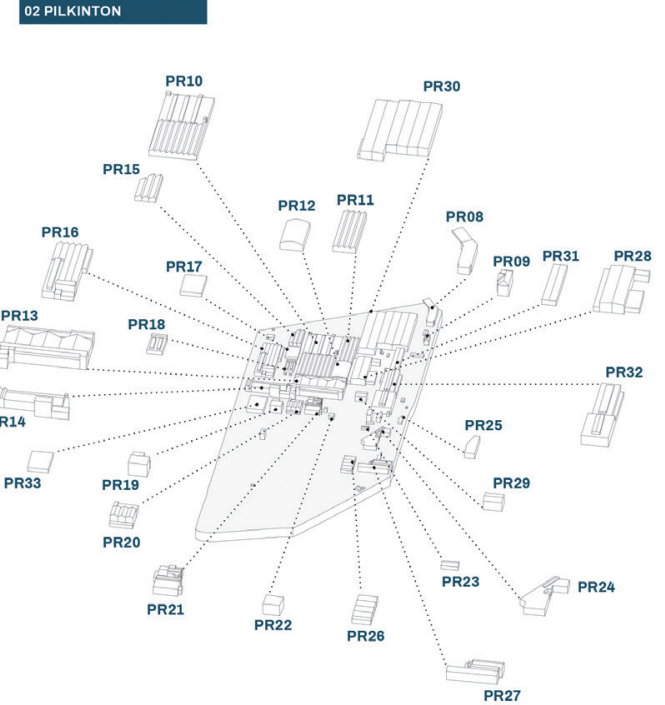

\section{Catálogo Porto Marghera}

Con este proyecto se han investigado las modalidades de análisis y mapeado el distrito industrial veneciano de Porto Marghera. El trabajo ha sido enfocado sobre el conocimiento y la comprensión de los lugares para detectar informaciones y personas involucradas en los procesos de transformación, y proporcionarles instrumentos útiles para una planificación a conciencia.

Como en el pasado, hay un áspero debate entre los diferentes objetivos (político, administrativos, empresariales y académicos) y las diversas maneras de actuación, cosa que resulta ser extraña si se tiene en cuenta que las autoridades responsables involucradas (ayuntamiento, provincia, región, autoridad portuaria, Confindustria etc.) pertenecen al mismo sector político! A la vez, hay que lidiar con actitudes egoístas que tienden a defender autonomías que siguen siendo incapaces de emprender un diálogo exitoso y proactivo en una visión unitaria.

A raíz de los fallos del pasado y la actual inmovilidad, se ha decidido hacerse cargo de los conocimientos adquiridos y de las múltiples experiencias 

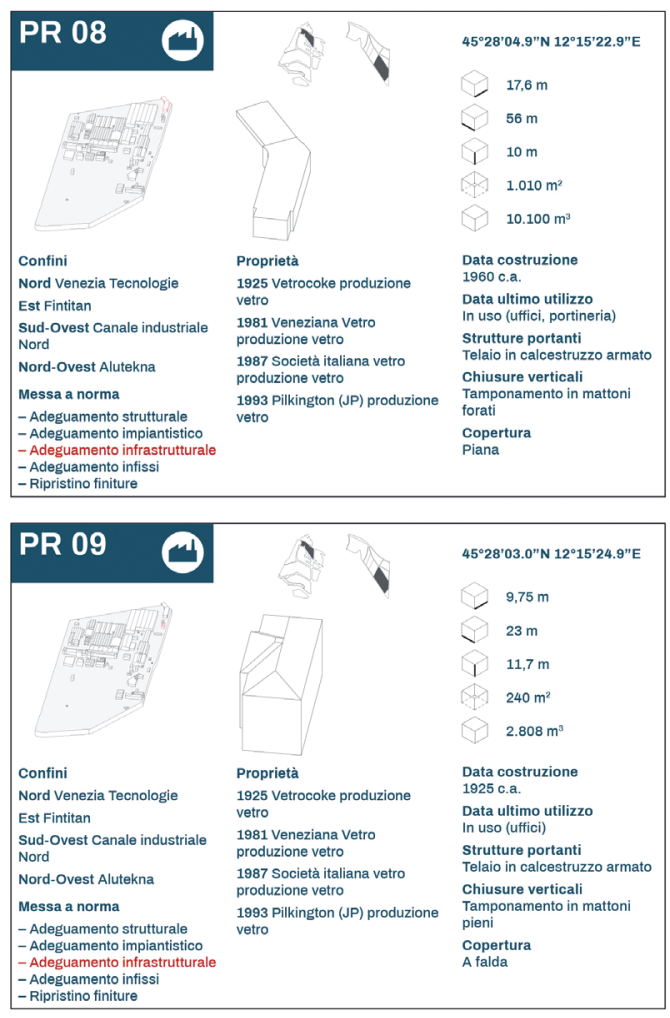

Fuente: Porto Marghera Atlas, 2018

fracasadas. Esto quiere decir que en esta fase de la investigación no hay planes para la creación de nuevos proyectos; hemos intentado elaborar una "guía" que reúne todas las nociones fundamentales del distrito industrial veneciano, de la misma manera que se haría para una obra de arte u otra disciplina. De la misma manera, hemos intentado leer y mapear las consecuencias negativas que la producción industrial ha dejado grabadas en el territorio. Este trabajo, más que guía se define catálogo de los elementos que forman parte y componen Porto Marghera.

\subsection{Propuesta de un método}

Lo que se ha experimentado es un planteamiento metodológico de tipo "inductivo" que se basa en la clasificación y la catalogación. Se ha intentado descomponer el fenómeno Porto Marghera en varias facetas: la historia (y la memoria) de estos sitios; la lógica de desarrollo de la producción industrial de los años que vieron
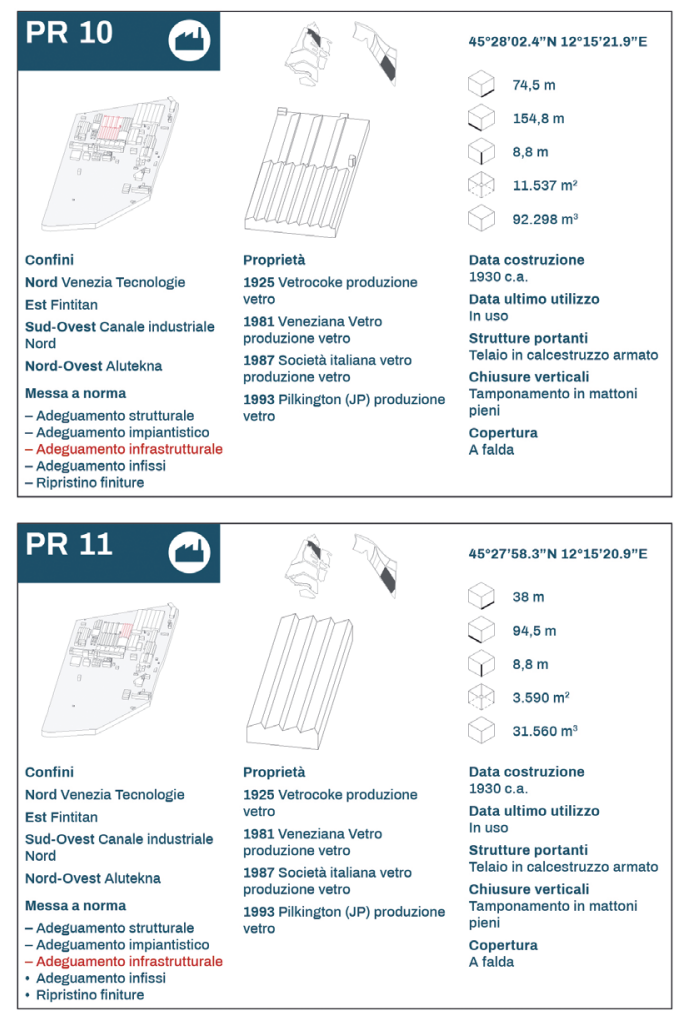

Porto Marghera en el liderazgo de progreso y modernidad; las consecuencias negativas y las difíciles herencias de la producción industrial (ambientales, sociales y urbanas); las posibilidades que Porto Marghera actualmente ofrece; todas las ambigüedades sin aclarar (competencias, interés público y privado, competencias administrativas, instrumentos legales).

Hemos estado involucrados en este proyecto con esfuerzo y dedicación por cinco años, en el intento de recomponer esta compleja realidad con el apoyo de datos experimentales supuestamente "irrelevantes"11. El propósito se ha conseguido gracias a significativas tomas de muestras: Ios análisis evidentemente se han realizado por partes y han sido fichados juntos a los datos ya recopilados.

11. «(...) lo que caracteriza este conocimiento es la capacidad de entender una realidad compleja pero no experimentable directamente mediante detalles experimentales supuestamente irrelevantes». Ginzburg C. (2000). Spie. Radici di un paradigma indiziario. En Mitiemblemi e spie. Morfologia e storia. Turín: Einaudi. p.166. (Texto original en Italiano) 
Esta prospección histórica, funcional, morfológica y tipológica intenta definir la urbanidad de Porto Marghera que, junto al contexto socioeconómico y ambiental, contribuye a definir su representación. El proceso no se inicia desde objeto, es decir de Porto Marghera, si no del fenómeno: el sistema de fichas permite organizar los datos en ábacos fenomenológicos (con claras repercusiones arquitectónicas).

Por lo tanto, las investigaciones son de hecho una lectura funcional y una lectura de estructuras formales: hay conciencia que pueda no ser la realidad de Porto Marghera sino simplemente una representación parcial que probablemente nunca se llevará al cabo, sin embargo, resulta útil a la hora de descomponer y entender el tema en su totalidad y recuperar, gracias a la abstracción, una imagen más consciente.

Una vez que definidos los ámbitos investigados y las categorías de síntesis, las informaciones han sido (re)ensambladas y diagramadas: se ha utilizado la estrategia de la superposición y del ábaco organizando los datos en fichas de síntesis por argumento, recopiladas finalmente en un manual. De esta forma, abstracción y representación ayudan a explicar, destacar, compartir o superponer los datos (para que sean evidentes los "puntos de contacto") que en caso contrario se quedarían separados en varias áreas especializadas. El propósito de un manual, por lo general, es efectivamente el de simplificar la comprensión y guiar iniciativas para obtener éxito en uno o más aspectos del tema tratado. Al ser una herramienta para consultas frecuentes, la comunicación del manual es fácil e intuitiva, paradigmática y pragmática al mismo tiempo. Entre sus propósitos, por lo tanto entre sus métodos de divulgación, está la identificación de una posible estrategia para enfrentarse a un sistema realmente articulado: este trabajo se propone facilitar trayectos operativos.

\subsection{Herramientas de investigación}

Para que el área resultara más "manejable", ha sido individualizada simplemente por la medida de las ínsulas definidas por el recorrido de
Ios canales y por la viabilidad. De esta forma, obtuvimos once áreas: 1 pequeña, 6 medianas, 2 grandes y 2 extra-grandes. Para destacar y compartir los datos que se encontraban dentro de secciones de conocimiento especializados, es decir para que la investigación fuera un aprendizaje de preceptos prácticos esenciales, hemos utilizado la estrategia de la superposición, del ábaco y del catálogo. Los datos desagregados han sido sucesivamente re-mapeados y diagramados por tipología y argumento.

En el distrito dividido de dicha forma han sido investigadas temáticas diferentes, desde la génesis de la Operación Porto Marghera, hasta los escenarios, aceptados o negados, que se han ido sucediendo en la historia de este sitio. Han sido recolectados los planos originales de los proyectos más importantes del desarrollo del puerto al principio del siglo veinte, poniendo el enfoque sobre los profundos cambios que han sufrido los propósitos del puerto: primero la perspectiva sobre la expansión del puerto comercial, y luego sobre las perspectivas de desarrollo de un puerto de vocación industrial. Además, se han vuelto a hacer los planos de todos los proyectos y transformaciones que han cambiado la morfología del borde lagunar entre el 1600 y el 2000. Dichos planos nos permiten ejemplificar y "serializar" las transformaciones aclarando la entidad de los cambios desde un punto de vista morfológico y de impacto territorial. Paralelamente se han devuelto los proyectos que por alguna que otra razón no se pudieron cumplir: transformaciones versus escenarios negativos. A una primera descomposición y clasificación por forma y dimensión, sigue el muestreo de todas las naves industriales estudiadas organizándolas por familias funcionales: producción, desplazamiento y almacenamiento. Este proceso permitió comprobar la densidad de lo construido en cada área, y establecer una primera base de datos de los objetos arquitectónicos. El ábaco facilitó la organización de las diferentes áreas utilizando como parámetro, por ejemplo, la densidad. Las mismas áreas que por dimensión se clasificaban como extra-grandes resultaron extra-pequeñas considerando la cantidad de silos de almacenamiento. 
Figura 10: A el análisis morfológico y funcional, siguió un estudio tipológico, para entender las vocaciones (pasadas y planeadas) y obtener un conocimiento más profundo del patrimonio arquitectónicos, urbanístico, histórico, o sea cultural de Porto Marghera. Ejemplo de una hoja de catálogo, capitulo "edificios para el deposito": Edificios verticales: silos.
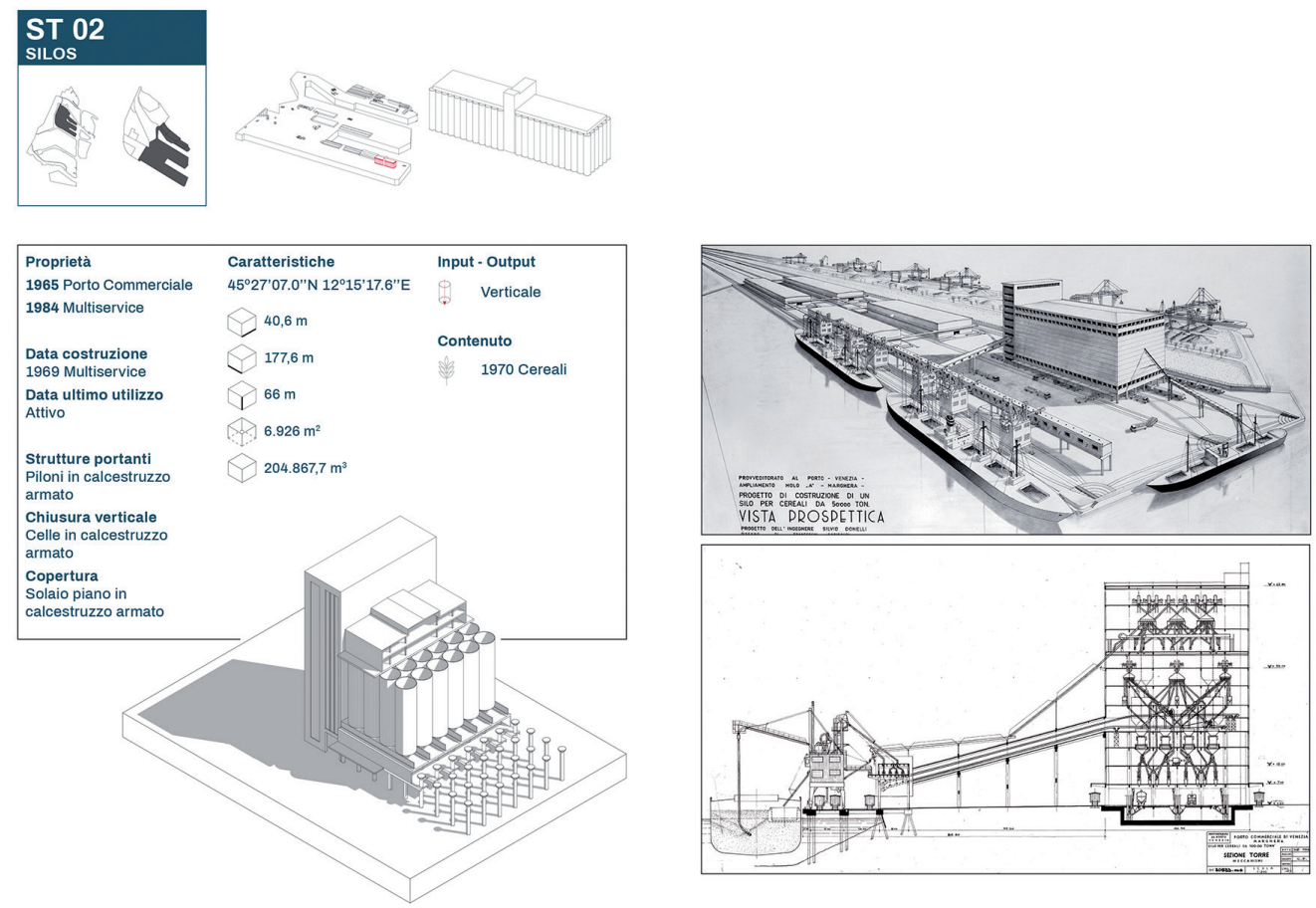

Fuente: Porto Marghera Atlas, 2018

Figura 11: Ejemplo de una hoja de catálogo, capitulo "edificios para el movimiento": Edificios altos: Torre de enfriamiento de agua
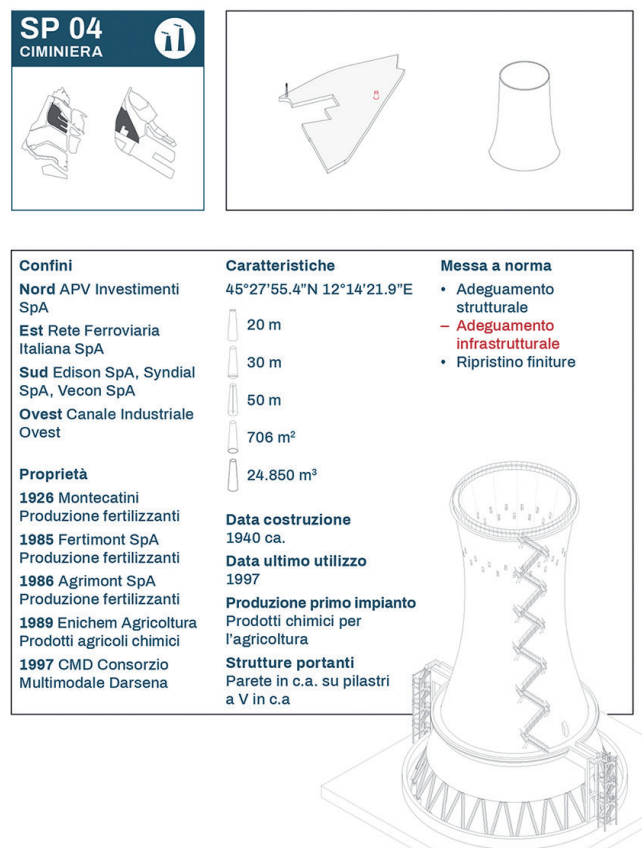

Fuente: Porto Marghera Atlas, 2018

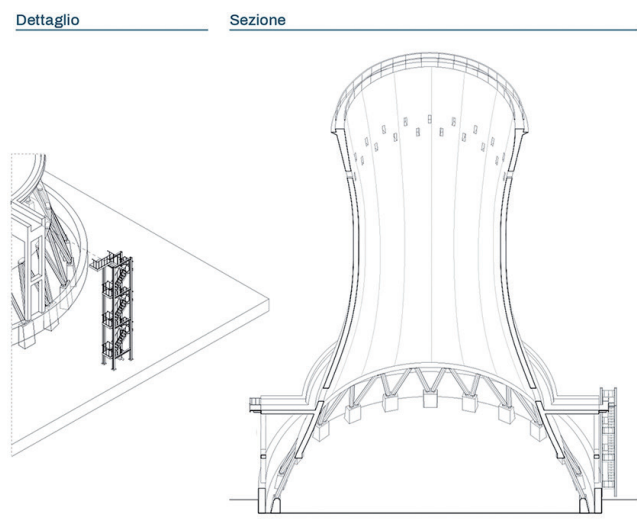

Pianta

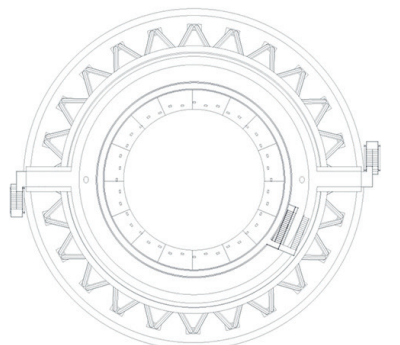


Figura 12: Esta investigación proporciona los datos necesarios para definir los parámetros de selección de los puntos neurálgicos donde poder implantar una posible (y plausible) acción de recomposición del distrito veneciano. 13 puntos focales seleccionados
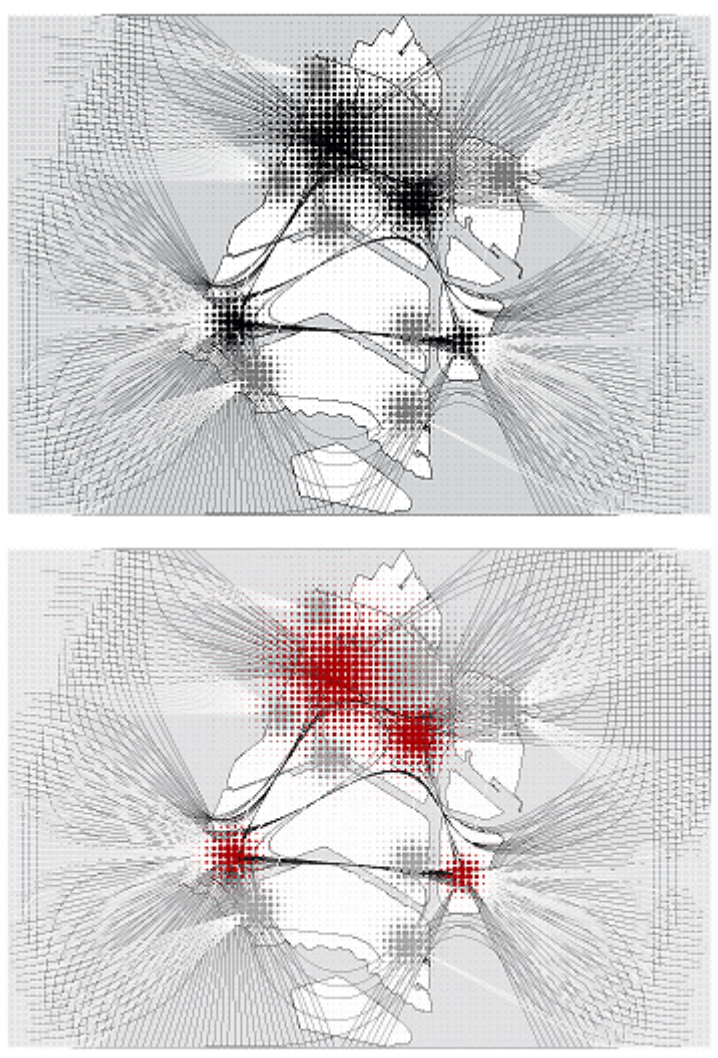

Fuente: Porto Marghera Atlas, 2018

Cada tipología funcional se ha puesto al centro de matrices y análisis, impulsando la creación de puntos de vista alternativos. A este análisis morfológico y funcional, siguió un estudio tipológico, una lectura de las características de los objetos mapeados anteriormente para identificar el valor documental (de la historia del lugar) y entender las vocaciones (pasadas y planeadas), para finalmente obtener un conocimiento más profundo del patrimonio arquitectónico, urbanístico, histórico, o sea cultural de Porto Marghera. El sentido de esta elección se funda en la convicción de que la custodia del patrimonio tiene valor cultural, que no se traduce en la conservación de manufacturas dirigidas a museos donde se mantendrán encerradas y cristalizadas en el espacio y en el tiempo como una memoria. Investigar y entender el valor documental sirve para poderlo utilizar como herramienta del proyecto. La memoria entendida como Cultura Material es uno de los vínculos que el proyecto de arquitectura tendrá en cuenta a la hora de dialogar; de hecho, se han
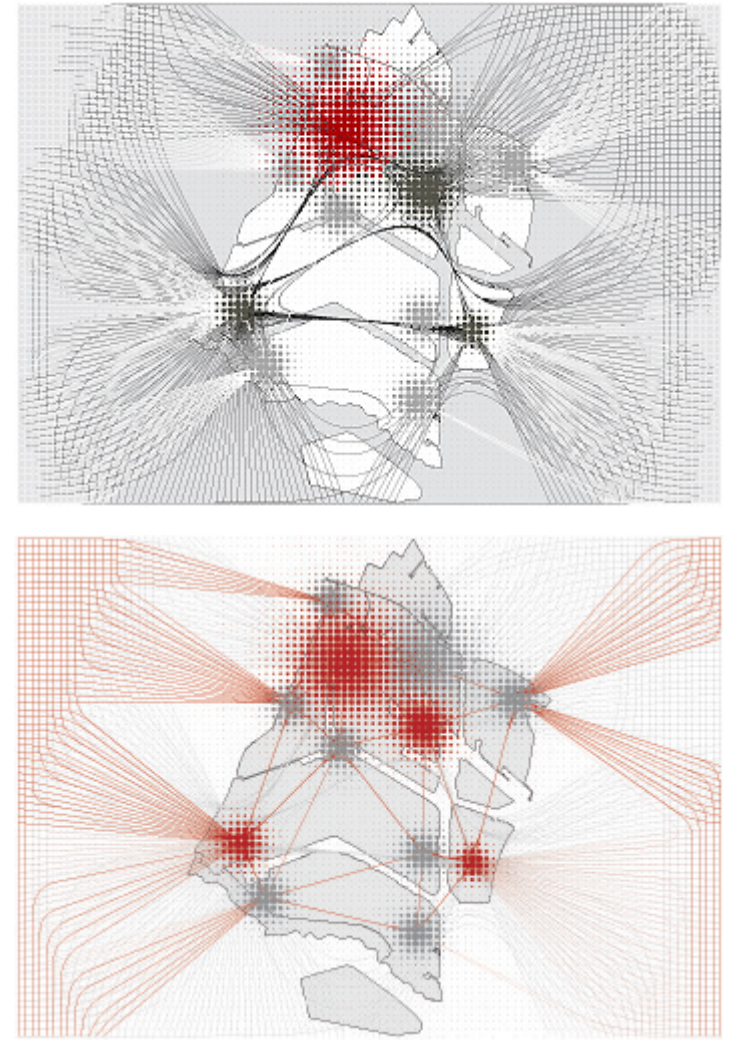

considerado en las fichas con la que se han organizado los ábacos tipológicos.

Esta investigación proporciona los datos necesarios para definir los parámetros de selección de los puntos neurálgicos donde poder implantar una posible (y plausible) acción de recomposición del distrito veneciano. 13 puntos focales seleccionados: edificios y / o áreas libres y en estado de abandono. Los que tienen en común: la presencia o la proximidad (distancia máxima: 500 m) a un edificio testimonio de la civilización industrial; el 75\% de estos puntos tienen una relación directa con el agua; los puntos son atendidos por las infraestructuras existentes; el 75\% de las áreas seleccionadas tienen proyectos de saneamiento aprobados y los niveles de contaminación están mapeados y comprobados (el resto de las áreas no han participado en los planes de caracterización). Se ha identificado un número suficiente de puntos para hacer sistema: un punto cada $1.5 \mathrm{~km} 2$ o menos (se va fácilmente a pie y en bicicleta). 


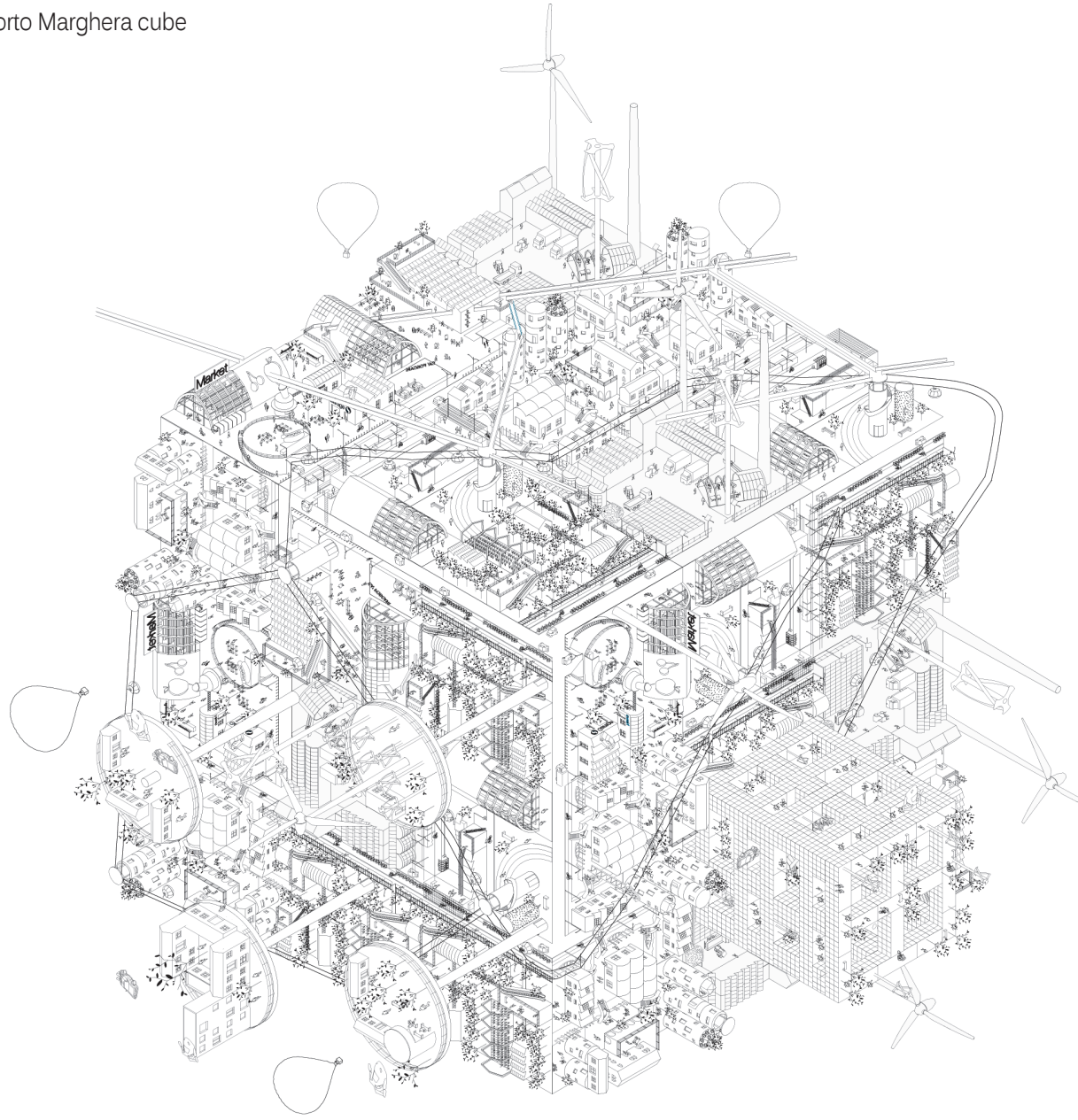

Fuente: @ Battilana-De Marchi-Scomparin. Porto Marghera Atlas, 2018

\subsection{Normativas y proyectos}

Otra sección del manual trata de recopilar las herramientas legales que localmente, nacionalmente y a nivel de la Comunidad Europea, han involucrado Porto Marghea a través de los años. Los parámetros (tiempos, costes, etc.) ${ }^{12}$ que han influido en el éxito (o el fracaso) de un proceso de rehabilitación, están todos asociados al compromiso ambiental y a la eficacia de los procesos de saneamiento. Por estas

12. La normativa establece que los costes para el financiamiento de la conterminazione sean amparados con financiaciones públicas, mientras que los costes del verdadero saneamiento de las matrices ambientales "debería" estar a cargo de los que causaron la contaminación o del dueño del terreno contaminado. En la realidad, resulta difícil establecer las competencias para el restablecimiento ambiental. El Masterplan del Saneamiento del 2004 estima un costo para las áreas sometidas a vertidos de 2.200.000 euro/hectárea y un coste de 1.300.000 eros/hectáreas para las áreas adyacentes. razones, un capítulo importante del trabajo de investigación considera la condición ecosistémica del distrito industrial veneciano y devuelve por un lado el nivel de alteración de las matrices ambientales: suelos y agua; por otro lado, fotografía la obra en curso de los procesos de saneamiento. Descifrar y detectar posibles estrategias de gestión del proceso de saneamiento, para poder reconducirlo hacia directrices arquitectónicas, es uno de los propósitos de la investigación. En este caso también se han utilizado instrumentos no disciplinares: prácticas económicas que han permitido trabajar con un sistema de matrices capaces de permitir la interacción entre el proyecto de saneamiento (conocimientos especializados) y el proyecto de arquitectura. La recalificación de los suelos comprende decisiones que involucran la morfología de los lugares, que no es trivial y además tiene múltiples opciones posibles y sostenibles. 
Donde hay que tomar una decisión, el arquitecto puede y tiene que interactuar.

\subsection{Oportunidades y finalidades}

La última parte del trabajo se centra en las dos mayores transformaciones actualmente en curso en Porto Marghera: se ha intentado entender si la complejidad del sistema, de alteraciones y procesos de rehabilitación, condiciona solo los tiempos y los costes del Proyecto o si influye en sus modalidades y funcionalidades de la recuperación. Esta investigación sobre Porto Marghera está pensada como un proyecto en continuo desarrollo que no puede ser llevado a cabo, pero que tiene la ambición de aclarar cómo moverse entre la asombrosa cantidad de datos, de intereses y de ambigüedades. La recopilación de los resultados no se tiene que entender como un instrumento legal, sino como un diccionario capaz de traducir las especialidades en potencialidades disciplinares; números en espacios; datos en las tipologías.

Este "Catálogo Porto Marghera" puede convertirse en el sitio donde recolectar y colocar las pruebas materiales e históricas que quedan; el sitio donde encontrar las herramientas de evaluación para que resulte más sencillo planificar cualquier intervención o transformación de lo que ya existe.

\section{Análisis y proyecto}

«Soy un creador de reglas. Y una vez creadas las reglas, creados estos juegos, creados estos mecanismos, puedo jugar yo, o puedo hacer que los demás jueguen.» ${ }^{13}$

Como introducción intentaremos definir lo que se considera el "móvil crítico", es decir la razón para la sistematización de los materiales recolectados en cinco años de investigación: el origen de la idea proyectual, el "estado naciente", el momento en el que la idea adquiere una forma y un sentido manifestándose a través de trazas, signos y núcleos figurativos.

13. Boetti A. (2017). Minimum/Maximum. Exposición en Venecia, Isla de san Giorgio Maggiore.
Es muy importante recordar que vincular el proyecto con los móviles iniciales es un arduo esfuerzo: los motivos del sito existen, pero las diferentes culturas y sensibilidades de cada proyectista llevan a notar solo los signos que aparecen funcionales al observador. Y concretamente en el tratamiento del caso de Porto Marghera aceptamos esta "fragilidad" característica de nuestra disciplina: las razones proyectuales y las lógicas que se reconducen al sólido código disciplinar llegan "después" de la idea, y son diacrónicas posteriores a la inspiración inicial, a la figuración.

El caso de Porto Marghera se vuelve emblemático: teniendo ya un vasto repertorio de análisis experimental (con proyectos de investigación aplicada y con el enfoque didáctico es decir en asignaturas y proyectos de tesis desde el año 2000), creemos que la ocasión compositiva, la inicial elección figurativa, el pretexto, no condicionan la calidad del proyecto. Puede ser adoptado libremente, y de la misma forma puede ser impuesto por parte de otros sin añadir o quitar nada al resultado final, que de por sí depende de otras capacidades. La creatividad de un arquitecto no se evaluará en función de su actitud y su tendencia a proponer novedades ${ }^{14}$, sino que se encontrará en su capacidad de dar fuerza a lo que quiere comunicar con sus obras.

Las estrategias de observación, los principios que fundan nuestra capacidad de clasificación de los fenómenos, representan una parte importante del proceso proyectual. Las "formas en espera"15 y las sensaciones que cada uno percibe e intenta desarrollar dependen del tiempo, de la mentalidad ${ }^{16}$, y del interés del observador de cara al fenómeno observado. Interpretación y selección son asuntos teóricos aplicados a la observación metódica, rigurosa y cuidada de

14. Referencia a Borges y al poema Eclesiastés 1,9 que se refiere a:Nihil sub solenovum [nada nuevo bajo el sol].

15. Forme in attesa (en Italiano): Referencia a Paul Valery (1986). La caccia magica. Napoli: Guida [La-chassemagique: La caza mágica] Discurso pronunciado en el segundo Congreso Internacional de la Estética y la Ciencia del Arte (Paris, 1937).

16. Para entender mejor el concepto de Mentalidad como disciplina histórica autónoma, se haga referencia al trabajo de Marc Bloch y LucienFebvre sobre la revista «Les Annales». 
fenómenos que puedan llevar al desarrollo de hipótesis proyectuales.

La narración por imágenes en el Atlas representa una manera de análisis de un fenómeno que ha sido observado por mucho tiempo: Porto Marghera. Lejos de ser un catálogo de observaciones exactas, este catálogo representa el lugar donde la pluralidad de formas en espera han sido ordenadas y catalogadas según diferentes temáticas y jerarquías. Parafraseando a Lichtenberg, cada responsable de proyecto (arquitecto $u$ otro especialista) será capaz de "ver su propio arco iris"17.

La investigación intenta llegar al reconocimiento de un trayecto teórico-crítico experimental para comprobar y representar al mismo tiempo tanto unas líneas generales a nivel de lectura en un caso complejo como el de Porto Marghera, como en el nivel de especificidad a través de ejemplos tópicos y, consecuentemente, generalizables. En otras palabras: el Atlas es un proyecto de detección de principios y métodos para definir una estrategia "operante"18 para varios estados del proyecto. Cada futura modificación operada en porto Marghera, en las áreas y/o en los edificios tendrá que ser comparada con los materiales que ya se encuentran en el sitio: se tendrá que evaluar los potenciales de transformación, participar en la creación de nuevas relaciones, fortalecer las que ya existen o introducir nuevos elementos dinamizadores. Estamos invocando escenarios en los que el término composición vuelve a tener un sentido más apropiado, para que vuelva a entenderse como un acto de recolección, recolocación de formas y objetos ya presentes realizando nuevas combinaciones que les valoricen. La composición en general, no solo la arquitectónica, requiere una poética y una capacidad de reelaboración que no resulta trivial describir. Los motivos que llevarán a identificar las estrategias de modificación y conservación se tienen que buscar en la tríada vitruviana, que sigue siendo hoy en día una

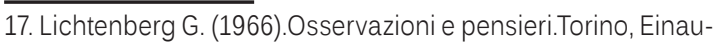
di. (Titulo original: Aphoprismen. Post. 1800-06)

18. "Operante" es una palabra italiana utilizada por F. Muratori (arquitecto y histórico de la arquitectura) en su libro: Studi per una operante storia urbana di Venezia (1960). Operante (eficaz) es la condición para que un estudio sea operativo. herramienta metodológica fundamental. Puede que haya razones funcionales (utilitas) que vincularán las decisiones sobre las intervenciones en elementos formales o estructurales, y que tenderán a mantener intacto el original destino de uso. En otros casos, las decisiones afectarán partes resistentes y estructurales que pueden ser (en un todo o solo parcialmente) transformadas en algo con un destino de uso totalmente distinto (firmitas). Finalmente, pueda que sea necesario tutelar el carácter formal del contexto considerado (venustas) para confirmar los caracteres morfológicos del lugar.

Analizar y leer el área de intervención, aun faltando un carácter puramente objetivo y científico, necesita llevarse a cabo con rigor y racionalidad. Dicho de otra forma: se tienen que dejar claros los "puntos de vista" del proyectista: esta es la primera y fundamental responsabilidad que desde siempre se la atribuye. Como ya se ha mencionado, dicho proyecto nace de la "contaminación" y fusión de conocimientos y experiencias. Hace falta un método concertado de intercambio de las hipótesis y sus transposiciones en proyecciones de síntesis y proyecto, para que se lleven a cabo con éxito los procesos de establecimiento de un sistema de referencia, ordenamiento de las observaciones, filtro de los datos y clasificación de las informaciones recopiladas. El proyecto se vuelve un lugar de relaciones: recomposición de diferencias, de elementos descartados, restablecimiento de un equilibrio entre memoria y futuro.

\section{Atlas, catálogo y manual}

Atlas es un catálogo de elementos que componen Porto Marghera. En esta investigación se asume que se necesita establecer un diálogo con lo que se puede leer en las preexistencias del sitio, para poderlos valorizar o descartar según las sensibilidades y las referencias culturales individuales. Como se ha explicado anteriormente, se considera el análisis de un lugar ya un proyecto. La forma en la que se observa un paisaje, un espacio urbano o una arquitectura, representa una expresión de la imaginación como filtro de la realidad. «Cada variación supone un orden reconocible para que se la 
Figura 14.1: Porto Marghera: el Puerto, 2003

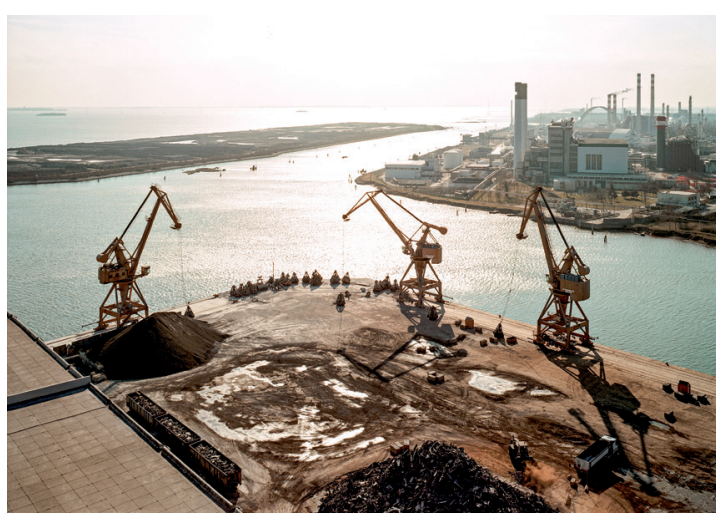

Fuente: (c) Fulvio Orsenigo. Porto Marghera Atlas, 2018

Figura 14.3: Porto Marghera: el área Sava 2004

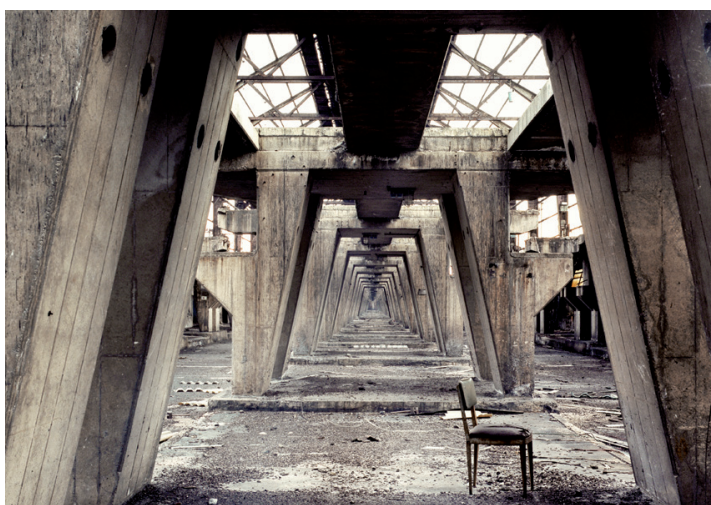

Fuente: @ Fulvio Orsenigo. Fuente: Porto Marghera Atlas, 2018

pueda apreciar» ${ }^{19}$. Ordenar esta percepción compleja y sincrética siguiendo secuencias lógicas y - como estamos intentando - según un protocolo de adquisición de informaciones y datos, es parte del esfuerzo de prefiguración del proyecto.

Estas estrategias, incluso si no plenamente conscientes, se llevan a cabo de todas formas, como sugerencias o impresiones.

En los manuales de arquitectura clásica, la visión sinóptica de las posibilidades morfológicas de un tema se debe al sistema de ábacos que junta todas las figuras posibles. El ábaco vale tanto para estudiar el orden de las

19. Carnevale, G. (2006). Variazioni. En A regola d'arte. Roma: Officina ed. p.144.
Figura 14.2: Porto Marghera: el área Agrimont Azotati, 1997

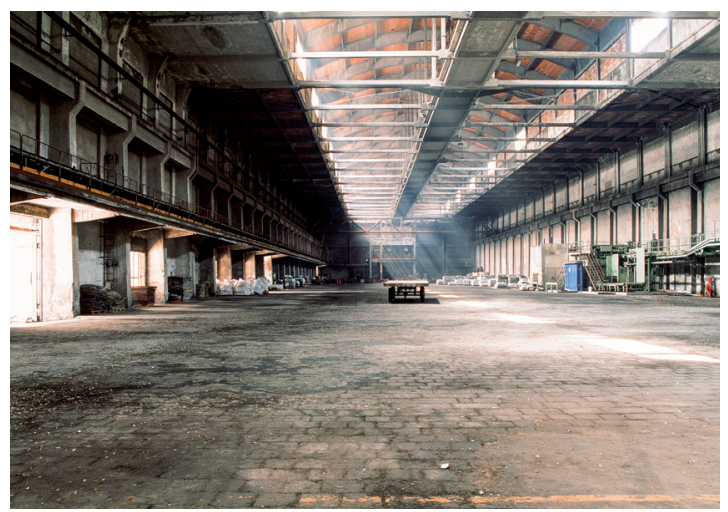

Fuente: (c) Fulvio Orsenigo. Fuente: Porto Marghera Atlas, 2018

Figura 14.4: Porto Marghera: el área Agrimont Agricoltura 1998

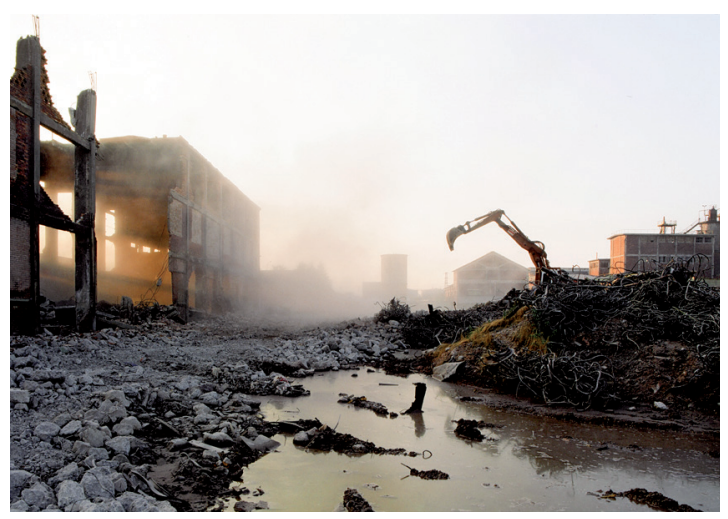

Fuente: (c) Fulvio Orsenigo. Fuente: Porto Marghera Atlas, 2018

columnas cuanto para los encastres en madera, tanto para las tipologías arquitectónicas cuanto para las variaciones tipológicas de un único tipo. Para nosotros, el ábaco es una herramienta de orden, multiplicador de formas pertenecientes a una familia de vínculos, detector de las fronteras entre las que hay que elaborar reflexiones. Cada ábaco tiene un corolario diferente que le da un sentido. El ábaco es algo prestado por el coleccionista, el entomólogo, el recolector de indicios que reside en nosotros, empezando por los "Objet Ambigu" de Valery ${ }^{20}$.

20. Paul Valéry en su breve dialogo Eupalinosoul'Architect, pone Socarte delante de un "objet ambigú": un objeto que el mar ha devuelto, que no puede ser explicado en el ámbito de la ontología platónica y que no se parece a nada, pero no es amorfo. Con esta excusa, Valéry, utilizando la voz del maes-tro Platón, diferencia la poiesis de la naturaleza de la poiesis del arte caracterizando la primera como producción de obras en forma perfecta, y las otras como solución para una tarea que 
Figura 14.5 : Porto Marghera: el área Agrimont Agricoltura 1997

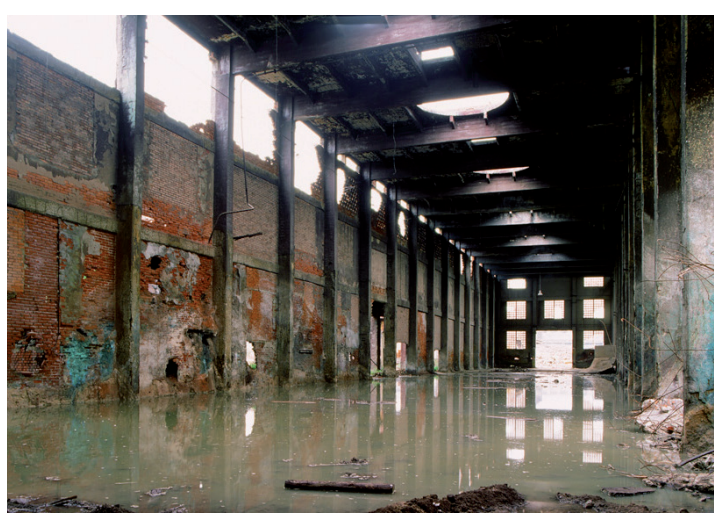

Fuente: ( Fulvio Orsenigo Porto Marghera Atlas, 2018

El desarrollo del proceso combinatorio ha abierto el camino a interpretaciones personales del fenómeno observado, que han llevado al descubrimiento de nuevas oportunidades e inspiraciones para ampliar el campo experimental inicial. Es un trabajo mecánico solo en apariencia, y que en realidad se propone ser riguroso debido a su origen inductivo: desde lógicas diminutas de principios constructivos, de elección de materiales, hasta lógicas compositivas. No intentamos eludir el inevitable impulso irracional que, más o menos conscientemente, nos lleva a inventar (raíz: invenio= encontrar) «algún que otro dispositivo que ponga en marcha la fantasía» ${ }^{21}$. Estamos de acuerdo con Poincaré que sea "avec l'intuition que nous trouvons" [en que es la intuición aquello con lo que encontramos] $]^{22}$.

Dicho de otra forma: estamos afirmando que el proyecto es una práctica racional; si admitimos que no sea así, se perderían todos los criterios científicos relacionados.

El proyecto es una secuencia de acciones lógicas y de argumentos, aunque originados en el concepto fundamental que es la intuición: "un coágulo sentimental", una sugestión fuerte, un

siempre resulta posible.

21. Conflicto entre los elementos de lo posible y lo real: Maurice Beutler, término "Fantastico" en Enciclopedia Einaudi.

22. "C'est avec la logique que nous prouvons et avec l'intuition que nous trouvons." Henri Poincaré.
Figura 14.6: Porto Marghera: el área Agrimont Agricoltura 1998

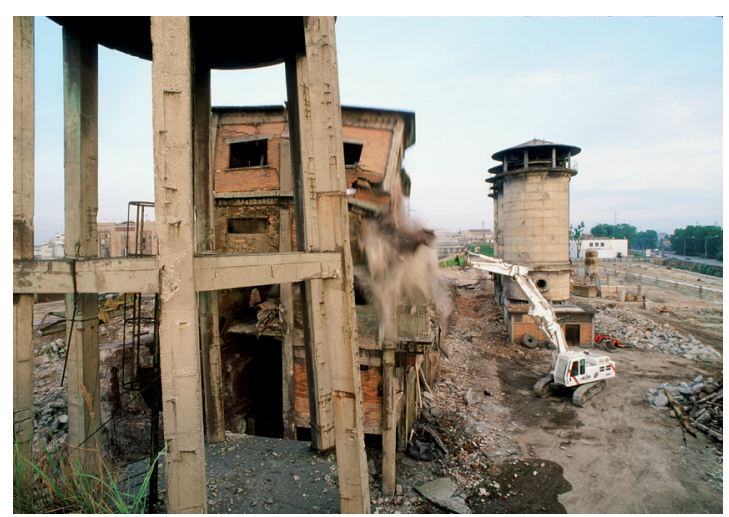

Fuente: @ Fulvio Orsenigo, Porto Marghera Atlas, 2018

pretexto, algún que otro dispositivo que ponga en marcha la fantasía. Podríamos concluir que este es exactamente el objetivo de nuestro experimento, basado en la búsqueda combinatoria, en las permutaciones compositivas, en la multiplicidad de las respuestas proyectuales compatibles: «El movimiento, el descarte que la abrumadora individualidad proyectual determina en el telar analítico más riguroso. La racionalidad no sería la que es si no incluyese, escondidas entre las sombras de sus propios rigores lógicos, las inquietudes de su propia memoria emotiva». (Carnevale, 2014)

\section{Conclusiones}

Esta investigación se trató de un camino de aprendizaje definiendo un proyecto de análisis. Análisis organizados en un sistema para un proyecto: Atlas es un proyecto para el proyecto. La narración de las figuras presentes en el paisaje de Porto Marghera es un repertorio, un conjunto que se utiliza para el desarrollo de pensamientos compositivos combinatorios. Elementos de escenarios potenciales donde sea posible encontrar el espíritu del tiempo presente, pasado y futuro.

Los análisis han mostrado una evidencia objetiva: que la parálisis de los procesos de recuperación en áreas tan dañadas como Porto Marghera están muy condicionadas por asuntos económicos. Estudios comparativos y análisis concuerdan en identificar la causa de este asunto: por una parte, 
el coste ecológico y sanitario necesita una base legal y política estable, por ser parte del bienestar público de la comunidad; por otra parte, se necesita que los costes sean económicamente sostenibles para los inversores privados que participan en la recalificación tanto de áreas como de manufacturas. El mismo historial de Porto Marghera representa un enlace indisoluble entre el bien público y el bien privado, y entre interés público e interés privado.

No es posible enfrentarse a la complejidad tan estratificada e inestable como las representadas por la historia de Porto Marghera, confiando en el simple conocimiento directo de lugares y hechos. La sociedad a menudo hace preguntas confusas: demarcamos firmemente el rol "anticipatorio" de la demanda real, que puede cierta-mente ser delegada a la Academia. Estudios e investigaciones relativos a necesidades actuales, quizás todavía no tan evidentes pero presentes en el territorio como problemática, son potenciales temas de investigaciones experimentales.

Con respecto a la compleja condición de Porto Marghera, el mayor distrito industrial italiano - y donde conviven áreas en desuso, saneamientos en curso de obra, reconversión industrial, recuperación de suelos y patrimonios edilicios, modernización y readaptación de la red infraestructural - se destaca la falta de una visión global. Un proyecto de coordinación, un acuerdo programático podría definirse juntando todas las pequeñas piezas que hemos analizado. Este es el riesgo de que todo se quede en un escenario hipotético hasta que no se encuentren y se reúnan la seriedad política y los recursos económicos. Cuando Porto Marghera consiga ser considerado una inversión prometedora y capaz de atraer los capitales necesarios, será posible abrir el camino a las transformaciones. De lo contrario hará falta contener las intervenciones, tratándolas como fundamentos estratégicos para un futuro cambio.

\section{Agradecimientos}

Estas notas cuentan lo que hemos recopilado en el volumen Porto Marghera Atlas (Giani, Peron, 2019), que se ha beneficiado del apoyo de muchas personas (compañeros, estudiantes, investigadores, becarios, estudiantes de fin de grado, fin de master y doctorado) y de muchas instituciones y archivos. La Universidad IUAV de Venecia y el Departamento de Arquitectura Construcción Conservación han financiado las investigaciones. La unidad de investigación, Giancarlo Carnevale, Irene Peron y el colectivo PREtesti. La traducción es de la joven investigadora Elisabetta Zuccatti y la inestimable supervisión de la amiga y compañera Marcela Brkljacic de la FAUD-UM (Mendoza). Gracias a Leandro Varela que nos ofreció la oportunidad de abrirnos hacia nuevas fronteras internacionales.

\section{Bibliografía}

Bachelard G. (1975). La poetica dello spazio. Bari: Dedalo Libri.

Bettin, G. Dianese, M. (2002). Petrolkiller. Milano: Feltrinelli.

Beutler M. (1982). Término "Fantastico" en Enciclopedia Einaudi.

Borges J.L. (1982). La Cifra. Milano: Mondadori.

Carnevale G. (1999). Litanie e Griffonages. Roma: Officina ed.

Carnevale G., Giani E. (2014). Occasioni di ricerca ovvero il nuovo che arretra. Mialno: Gangemi ed.

Carnevale, G. (2006). A regola d'arte. Roma: Officina.

Eco U. (2010). Opera Aperta. Forma e indeterminazione nelle poetiche contemporanee. Milano: Bompiani ed.

Giani E., Peron I. (2019). Porto Marghera Atlas. Barcelona: ListLab.

Ginzburg C. (2000). Miti emblemi e spie. Morfologia e storia. Torino: Einaudi.

Lichtenberg G. (1966).Osservazioni e pensieri.Torino, Einaudi.

Muratori S. (1960). Studi per una operante storia urbana di Venezia. Venezia: Marsilio.

Poincaré H. (2013). Works of Henri Poincaré. London: The Perfect Library. 
Settis, S. (2014). Se Venezia Muore. Torino: Einaudi.

Valery P. (1986). La caccia magica. Napoli: Guida ed.

Valery P. (2010). Eupalinos o l'architetto. Milano: Gangemi ed.

Zenghellis E. (2007). The "immeuble-cité"a strategy for Architecture.En PowerNotes \#06, 3rd International Architecture Biennale Rotterdam. 